SAE paper 2005-01-2292. Copyright (C) 2005 SAE International. This paper is posted on this site with permission from SAE International, and is for viewing only. Further use or distribution of this paper is not permitted without permission from SAE 


\title{
Development of a Clunk Simulation Model for a Rear Wheel Drive Vehicle With Automatic Transmission
}

\author{
Ashley R. Crowther and Nong Zhang \\ Faculty of Engineering, University of Technology, Sydney \\ Rajendra Singh \\ Acoustics and Dynamics Laboratory, Centre for Automotive Research, The Ohio State University
}

Copyright $\odot 2005$ SAE International

\begin{abstract}
A reduced model is developed for transient analysis of gear rattle in an automatic transmission (AT) powertrain. Linear modal analysis for the reduced order model compares well with a detailed model that includes planetary gear dynamics. Clearance type lash functions are used for the reduced geared coordinates of the automatic transmission and final drive. Impacts within the gear pairs are affected by the engine surging, shaft stiffness, component inertias, engine harmonics, drag torques, braking, viscous damping and vehicle load. The occurrence of these impacts, or clunk, from shuffle and axle oscillations is demonstrated under typical driving conditions.
\end{abstract}

\section{INTRODUCTION}

Appropriate dynamic models are needed to understand and to improve vibration transients in vehicle powertrains, especially in automatic transmission (AT) equipped powertrains and those with constantly variable transmissions (CVT) as they present significant challenges for engineers with many non-linearities. A specific area includes models that capture transient vibration during parametric gear shifting and/or throttle change. Hwang et al. and Jo et al. [1-2] developed models and simulations for gear shifting for various systems and provided some experimental correlations. Zhang et al. [3] presented a finite element method for gear shifting. Zhang et al. [4] developed a model and simulation for a CVT equipped powertrain. These simulations are parametric in shifting and include nonlinear time-varying forcing functions as well as harmonic excitations. Further studies of transient vibrations of the elastic system under the influence of multiple nonlinearities are needed; it is the focus of this article.

Shuffle is vibration of the lowest global torsional mode [5]. Transients occur at 2-10 Hz depending on gear ratio. It is largely dependent on the inertia of the engine and flywheel and overall compliance of the entire powertrain and the driveline system. It is particularly sensitive to the stiffness at the upstream end of the powertrain, whether flywheel shaft, damper clutch or equivalent $\mathrm{CV}$ unit or torque converter stiffness. Shuffle is excited by a rapid change in engine torque and brake torque, clutch engagements or gear shifting. Shuffle can be felt as fore-aft vibration in the passenger compartment. Clunk is noise from the impact of gears after they pass through the clearance between their backlashes [5]. It takes place on reversals of the direction of rotation of the gears. It is different from gear rattle which occurs at high frequency, typically on lightly loaded gears or unladen gears; this is excited by pulsating engine torque [6]. Clunk occurs due to changes in rigid body motion of a vehicle and thus static twist of powertrain compliances and the interaction of resulting transient vibration for the elastic system - e.g. shuffle. Stick-slip is the non-linear intermittent sliding (slip) and stick at a contact surface. It is a phenomenon with dependence on friction characteristics, system dynamics and external tangential and normal forces. Most studies concentrate on systems with the sliding interface between one moving and one stationary surface or between one moving and a substrate moving at a predetermined velocity. In automotive clutches the sliding interface is between two masses with undetermined velocities in a non-linear non-autonomous system; thus investigation using numerical methods is appropriate. Stick-slip was investigated by Crowther et al. [7] in AT systems and further a methodology was demonstrated for stick-slip and clunk in a simplified powertrain in [8].

Experimental testing has been used to investigate clunk and shuffle. Krenz [5] found clunk and shuffle to be more severe with a higher rate of engine torque rise and increased driveline lash - but not necessarily in a linear manner. Splines were noted as a major source of lash and fluid couplings noted as highly effective for controlling clunk response. The lash between the flywheel and the differential output was found to be 8 degrees. Menday et al. [9] used a shock impulse to excite high frequency modes and lash impacts. They 
developed a finite element model for modal analysis of the propeller shaft and included this in a lumped-mass powertrain model. Farshidianfar et al. and Biermann et al. [10-12] report further work on modelling and testing for clunk and shuffle in manual transmission (MT) powertrains.

\section{OBJECTIVES}

In this paper, the clunk phenomenon is examined with dynamic simulations for a reduced AT powertrain model. Engine, terrain and braking transients are included to demonstrate clunk in a driving situation where it is likely to occur. The reduced model linear system response is compared with a detailed AT model. The planetary set is represented as a gear pair with appropriate lumping and ratio for the effective inertia of all components. Likewise for the final drive. Lash elements are included in both sets. Energy dissipation is applied by using a viscous damping matrix and by dynamic drag on the torque converter turbine as a function of mean speed. Results are presented demonstrating clunk and compared for low and high damping of driveline shuffle via turbine drag. The effect of rigid body motion and axle oscillations is demonstrated. The detailed model is then discussed for reduction for analysis of clunk during AT gear shifting with stick-slip and clutch engagement judder.

\section{POWERTRAIN SYSTEM SPECIFICATION}

The powertrain modelled is installed on a test bed in the Faculty of Engineering test cell at the University of Technology, Sydney. It is a test facility designed to capture the torsional dynamics of passenger vehicle powertrains. A flywheel system is driven by the tires in a fashion similar to road contact - the inertia of the flywheeis simulates the mass of the 'vehicle'. See Figure 1 for a photo of the rig. Seen in the photo (from left to right) are dynamometer (behind) and driven tires, flywheel inertia, driving tires, drivetrain, transmission and engine. The engine is a six cylinder spark ignition type. The automatic transmission is lon Automotive Systems' four speed 93LE. This transmission is described further in [3].

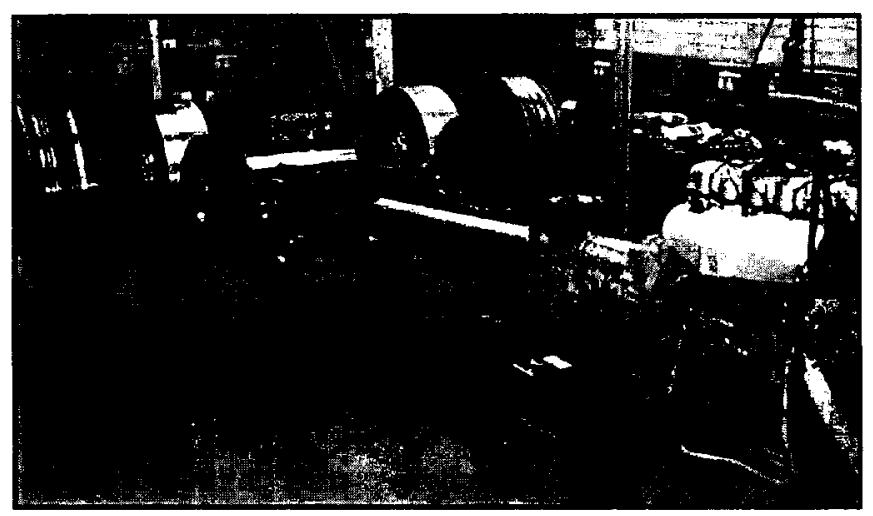

Figure 1. UTS Powertrain Test Rig

\section{POWERTRAIN DYNAMIC MODEL}

Figure 3 presents a dynamic model for investigating clunk in the AT powertrain system. Ten degrees of freedom (DOF) are assigned to significant lumped masses - TC turbine (including effective engine and impeller inertia), clutch drum, planetary gear driving and driven components, universal joint and propeller shaft inertia, final drive ring and pinion gears, wheel hub and tire/vehicle inertia. Note that the tires (and vehicle equivalent inertia) are modelled as one coordinate. The stiffness elements are transmission input shaft, forward sun shaft, output shaft, propeller shaft, tooth meshes, drive shafts and tire.

\section{TORSIONAL FINITE ELEMENTS}

The model is described with torsional finite elements. Inertia, stiffness and damping elements provide the relationship between local coordinates and are assembled with a global coordinate vector. Straight elements are used for shafts and tires. For example, the input shaft is given by:

$$
\mathbf{I}_{e 1}=\left[\begin{array}{cc}
J_{1} & 0 \\
0 & J_{2} / 2
\end{array}\right] \quad \mathbf{K}_{e 1}=\left[\begin{array}{cc}
k_{1} & -k_{1} \\
-k_{1} & k_{1}
\end{array}\right] \quad \boldsymbol{\theta}_{e l}=\left\{\begin{array}{l}
\theta_{1} \\
\theta_{2}
\end{array}\right\}
$$

Elastic geared elements are used for the transmission and final drive mesh. For example, the gear pair in the final drive mesh is described as follows (without the backlash):

$$
\mathbf{I}_{e 6}=\left[\begin{array}{cc}
J_{6} / 2 & 0 \\
0 & J_{7} / 2
\end{array}\right] \quad \mathbf{K}_{e 6}=\left[\begin{array}{cc}
r_{6}^{2} k_{6} & -r_{6} r_{7} k_{0} \\
-r_{6} r_{7} k_{6} & r_{7}^{2} k_{6}
\end{array}\right] \quad \boldsymbol{\theta}_{e 6}=\left\{\begin{array}{c}
\theta_{6} \\
\theta_{7}
\end{array}\right\}
$$

\section{GLOBAL SYSTEM ASSEMBLY}

The finite element matrices are assembled into global system matrices by using local coordinate vectors and the global coordinate vector. The equations of motion for the forced system in matrix form is:

$$
I \ddot{\theta}+C \dot{\theta}+K \theta=T
$$

For the reduced model fixed in second gear the global coordinate vector is fixed at 10 degrees of freedom:

$\boldsymbol{\theta}=\left\{\theta_{1} \ldots \ldots \ldots \theta_{10}\right\}$

The inertia matrix is:

$$
I=\left\{J_{1} \ldots \ldots . . . J_{10}\right\}
$$

The stiffness matrix is assembled from the finite elements according to the local coordinate vector. 


\section{SYSTEM PARAMETERS}

System parameters are given in Table 1; they have been carefully determined for the test rig and are approximate for a Ford Falcon AU RWD passenger car. Transmission gearing is $1: 1.47$ in second gear and for the final drive $1: 3.45$. The model provides very similar modes to that of a detailed system (Figure 4). Stiffness were summed in series and the lumped masses carefully redistributed to keep the same overall stiffness and inertia.

\begin{tabular}{|l|l|l|l|}
\hline$J_{1}$ & $0.235 \mathrm{kgm}^{2}$ & $J_{6}$ & $3.86 \mathrm{e}-3 \mathrm{kgm}^{2}$ \\
\hline$J_{2}$ & $1.62 \mathrm{e}-2 \mathrm{kgm}$ & $J_{7}$ & $5.33 \mathrm{e}-2 \mathrm{kgm}^{2}$ \\
\hline$J_{3}$ & $2.36 \mathrm{e}-3 \mathrm{kgm}^{2}$ & $J_{8 / 9}$ & $0.75 \mathrm{kgm}^{2}$ \\
\hline$J_{4}$ & $6.60 \mathrm{e}-3 \mathrm{kgm}{ }^{2}$ & $J_{10}$ & $151.2 \mathrm{kgm}^{2}$ \\
\hline$J_{5}$ & $8.53 \mathrm{e}-4 \mathrm{kgm}{ }^{2}$ & & \\
\hline $\mathrm{k}_{1}$ & $20600 \mathrm{Nm} / \mathrm{rad}$ & Input shaft \\
\hline $\mathrm{k}_{2}$ & $40700 \mathrm{Nm} / \mathrm{rad}$ & Forward sun shaft \\
\hline $\mathrm{k}_{3}$ & $5 e 8 \mathrm{Nm} / \mathrm{rad}$ & Transmission mesh \\
\hline $\mathrm{k}_{4}$ & $36600 \mathrm{Nm} / \mathrm{rad}$ & Output shaft \\
\hline $\mathrm{k}_{5}$ & $30600 \mathrm{Nm} / \mathrm{rad}$ & Propeller shaft \\
\hline $\mathrm{k}_{6}$ & $5 e 8 \mathrm{Nm} / \mathrm{rad}$ & Final drive mesh \\
\hline $\mathrm{k}_{7}$ & $11100 \mathrm{Nm} / \mathrm{rad}$ & Driveshaft right \\
\hline $\mathrm{k}_{8}$ & $9390 \mathrm{Nm} / \mathrm{rad}$ & Driveshaft left \\
\hline $\mathrm{k}_{9 / 10}$ & $22000 \mathrm{Nm} / \mathrm{rad}$ & Tire \\
\hline
\end{tabular}

Table 1. System Parameters for Reduced Powertrain Dynamic Model

\section{LINEAR ANALYSIS}

The eigensolutions are found for equation (1) with $T=0$ and $\mathbf{c}=\mathbf{0}$. There is one zero eigenvalue (rigid body rotation) and 9 non-zero eigenvalues which represent natural frequencies of the lumped torsional coordinates due to combinations of torsional elasticity and lateral bending at tooth contact. Their corresponding eigenvectors represent the mode shapes of response. The natural frequencies are given in Table 2. The rigid body mode describes the absolute displacements for the transmission in second gear and for final drive gearing. It can be seen that the frequencies of this reduced system compare very closely with those of the detailed powertrain system - for those modes captured by the reduced model. Mode shapes are compared in Table 4 for the first five modes. The main modes of interest $(6$ modes up to $600 \mathrm{~Hz}$ ) are captured closely by the reduced 10 DOF system.

\section{NON-LINEAR NUMERICAL ANALYSIS}

Consumers often report driveline clunk after coasting over the crest of a hill, i.e. the road changes from positive to negative gradient. So we have run simulations to investigate the problem with a combination of throttle tip-out and braking to maintain roughly a constant vehicle speed as a vehicle drives over a crest. The dynamic model is solved with these forcing functions representing typical excitation (induced by the driver behavior) and vehicle dynamics.
Transient analysis is performed with inclusion of:

- Mean engine torque with engine harmonics

- Engine tip-out function

- Road gradient vehicle load function

- Aerodynamic drag function

- Rolling resistance function

- Non-linear gear mesh stiffness (with backlash)

- Viscous damping matrix

- Turbine drag torques

For forced analysis the system of equations of motion for the dynamic model of (1) is modified. It is now a time varying non-linear system. The solution of the equations of motion includes the rigid body motion of the powertrain, forced frequency response spectra and nonlinear response. Gear backlash is treated as a clearance type non-linearity - with a piecewise function for the stiffness discontinuity. The simulation is programmed in Matlab using ODE15S, a solver that uses the Gear's Method for stiff Systems [12]. Results with Matlabs $4^{\text {th }}$ order Runge Kutta solver were the same but much slower.

\begin{tabular}{|c|c|c|}
\hline $\begin{array}{c}\text { Mode } \\
\text { description }\end{array}$ & $\begin{array}{c}\text { Natural } \\
\text { Frequency }(\mathrm{Hz}) \\
\text { (Reduced } 10 \\
\text { DOF Model) }\end{array}$ & $\begin{array}{c}\text { Natural } \\
\text { Frequency }(\mathrm{Hz}) \\
\text { (Detailed Model) }\end{array}$ \\
\hline Driveline shuffle & 6.54 & 6.41 \\
\hline $\begin{array}{c}\text { Global and axle } \\
\text { tramp }\end{array}$ & 32.3 & 32.1 \\
\hline Global and axle & 33.2 & 33 \\
\hline $\begin{array}{l}\text { Transmission } \\
\text { and Driveline I }\end{array}$ & 142 & 137 \\
\hline $\begin{array}{l}\text { Transmission } \\
\text { and Driveline II }\end{array}$ & 250 & 247 \\
\hline Transmission I & 532 & 476 \\
\hline Prop shaft I & 1405 & 1195 \\
\hline Prop shaft II & 1760 & 1709 \\
\hline Transmission III & 2500 & 2144 \\
\hline
\end{tabular}

Table 2. Natural Frequency Comparison

\section{GEAR PAIR LASH ALGORITHM}

Gear pair lash is the clearance between mating gears. In a loaded system meshing gears can lose contact during torque reversal. Within a certain range of lash the system is disconnected and the gear mesh stiffness is zero. When the gears reengage the mesh stiffness is a combination of tooth bending and material compression, the impact causes transient vibration and noise. The non-linear stiffness can be presented as restoring force as a function of relative position as shown in Figure 2. 
The algorithm used to model the gear lash is:

For mesh stiffness:

$k_{1}= \begin{cases}k_{1} & \text { if }\left|\left(x_{1 \text { rel }}\right)\right| \geq \delta_{1} / 2 \\ 0 & \text { if }\left|\left(x_{\left.i_{\text {ret }}\right)}\right)\right|<\delta_{1} / 2\end{cases}$

Where:

$x_{i r e l}=r \theta_{1}-r_{i+1} \theta_{i+1}$

And $\delta$ is the lash of each gear pair. With the gear mesh force, $F$, non-linear in this way the torque vector is needed to account for the offset of force from the zero position. The global torque vector includes the local torque offsets:

$$
\begin{aligned}
& T_{\text {lash }(i)}=-\operatorname{sign}\left(x_{i r e l}\right) r_{i} k_{i} \delta_{i} / 2 \\
& T_{l a s h(i+1)}=\operatorname{sign}\left(x_{i r e l}\right) r_{i+1} k_{i} \delta_{i} / 2
\end{aligned}
$$

When the stiffness, $k_{i}$, is found to be zero, the torque offset is returned as zero. The clearance is applied at the transmission mesh between coordinates 3 and 4 , $(i=3)$ and at the final drive mesh between coordinates 6 and $7(i=6)$. The lash for the transmission gear pair is set at $2 \mathrm{~mm}$ and for the final drive gear pair at $4 \mathrm{~mm}$. This could also be seen as inclusive of nearby lashes, i.e. splines and joints.

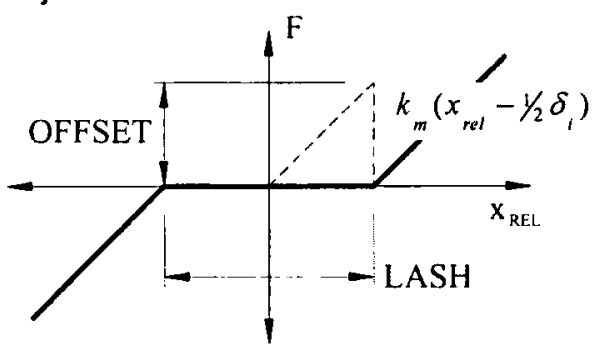

Figure 2. Non-linear gear mesh force function

\section{Viscous Damping}

Damping is difficult to determine in automotive powertrain systems. The damping from torque converters, tire elasticity and drag is highly non-linear. Shaft elements exhibit torsional hysteresis. Clutch dampers require much design for optimization of hysteresis etc. In this study we have applied damping in several ways to capture the effects in the solutions. First a viscous damping matrix is constructed with the same form as the stiffness matrix. However, damping of the shuffle mode is difficult with this matrix, without inclusion of a dynamic model for the torque converter. The viscous damping coefficients applied give the damping ratios shown in Table 4 . It can be seen that all modes apart from the shuffle mode are damped reasonably. Shuffle is damped at only $0.6 \%$. Increasing the tire damping or other physical damping elements will further dampen shuffle but with the unwanted effect of raising damping ratios or over damping other modes. Note, some 'heavy' inertias, i.e. engine and impeller, are not included in the model, though an effective inertia is added to the turbine. A modal damping matrix may be constructed to achieve fixed damping ratios for all modes (such as $5 \%$ ). The modal damping matrix is fully populated with a combination of negative and positive damping connections necessary to achieve high damping to the shuffle mode. For non-linear simulations, modal damping in some instances could cause the system to be numerically unstable - modal damping is appropriate for linear time-invariant systems. So to achieve sufficient damping for the shuffle mode, a dynamic drag damping element has been applied at the torque converter. In simulations this damping is applied in the torque vector as:

$$
T_{\text {drag }}=-D_{1}\left(\dot{\theta}_{1}-\bar{\theta}_{1}\right)
$$

Where $\overline{\dot{\theta}}_{1}$ is the mean speed of the turbine, sampled roughly at the shuffle mode (with solver max step $0.00005 \mathrm{~s}$ and sample vector of 4000 values the sampling frequency for max time stepping is $5 \mathrm{~Hz}$ ).

For free vibration analysis of the linearised system the mean speed is zero and the dynamic drag coefficient shifts into the damping coefficient matrix - as an absolute damping coefficient. With a coefficient of 2 $\mathrm{Nms} / \mathrm{rad}$ the shuffle mode damping ratio increases to $8.2 \%$ without affecting the other modes (Table 3 ). Sampling mean speed of the coordinates slows down the simulation somewhat and is not $100 \%$ accurate. However it achieves the desired purpose. The mean speed drifts slowly from the actual speed, however, the error only effects the solution in a similar fashion to a small constant turbine drag as the drift is slow. The dynamic damping effect is reasonably captured.

\begin{tabular}{|c|c|c|}
\hline Mode description & $\begin{array}{c}\text { Damping Ratio } \\
(\%)\end{array}$ & $\begin{array}{c}\text { Enhanced Damping } \\
\text { Ratio with Dynamic } \\
\text { Drag } \\
(2 \mathrm{Nms} / \mathrm{rad})\end{array}$ \\
\hline Driveline shuffle & $0.6 \%$ & $8.2 \%$ \\
\hline $\begin{array}{c}\text { Global and axle } \\
\text { tramp }\end{array}$ & $5.1 \%$ & $5.1 \%$ \\
\hline Gtobal and axle & $5.2 \%$ & $5.2 \%$ \\
\hline $\begin{array}{c}\text { Transmission and } \\
\text { Driveline I }\end{array}$ & $3.8 \%$ & $3.8 \%$ \\
\hline $\begin{array}{c}\text { Transmission and } \\
\text { Driveline II }\end{array}$ & $2.7 \%$ & $2.7 \%$ \\
\hline Transmission I & $2.5 \%$ & $2.5 \%$ \\
\hline Prop shaft I & $5.4 \%$ & $5.4 \%$ \\
\hline Prop shaft II & $1.8 \%$ & $1.8 \%$ \\
\hline Transmission III & $2 \%$ & $2 \%$ \\
\hline
\end{tabular}

Table 3. Modal Damping Ratios 


\section{CLUNK EXCITATIONS}

\section{Engine Torque}

Engine mean torque, $T_{\text {eng, }}$ is interpolated from the engine torque map using engine speed. Torque oscillations are added for a typical 6 cylinder engine. Throttle is initially $10 \%$ and at $t=4 \mathrm{~s}$ the throttle is reduced to $5 \%$ over $0.2 \mathrm{~s}$, as shown in Figure 6 . The engine torque is applied directly to the turbine.

\section{Braking Torque}

Brake torque, $T_{D}$, is applied to simulate a driver pressing once on the break and releasing - a tap. The driver then presses again and holds constant breaking torque. A braking model is simplified to conceptually capture the qualitative nature of such driver behavior. The torque is applied to the hub coordinates as a piecewise function using linear and constant functions of time. It should be noted that for the powertrain model the brake rotor is lumped with the mass at the hub coordinate. Relative to driveshaft and tire compliance the rotor and hub are very rigidly connected. The brake torque is applied at $4 s$ (first tap) and 4.5s (brake and hold), also shown in Figure 6.

\section{Road Gradient Vehicle Load}

The road profile is modelled with a parabolic curve (Figure 7). For the sake of illustration, the curve describes a hill $100 \mathrm{~m}$ wide and $5 \mathrm{~m}$ high. The path of the vehicle along the equation of the curve is determined dynamically from the absolute angular displacement of the tire. Note that tire slip is not included in this dynamic model; otherwise, it would need to be accounted for here. At initial condition, $t=0$, the vehicle longitudinal position, tire angular displacement and road gradient are:

$$
x_{(t=0)}=-50 \quad \theta_{10(t=0)}=0 \quad \psi_{(t=0)}=0.197
$$

This initial road gradient is a maximum and in degrees is $11.31^{\circ}$. Each new time step the longitudinal position and gradient are determined by:

$x_{(i)}=x_{(t-1)}+r_{W} \cos \psi_{(i-1)}\left(\theta_{10(t)}-\theta_{10(1-1)}\right)$

$\varphi_{(t)}=\tan ^{-1}\left(x_{(t)} / 250\right)$

Values of $x_{(1)}$ and $\varphi_{(t)}$ are stored to be used as $x_{(t-1)}$ and $\varphi_{(t-1)}$ on the following time step. The resisting torque

(Figure 6) on the tire from the weight of the vehicle is determined from the vehicle mass and road gradient:

$$
T_{\text {grad }}=m_{v e h} g \sin \left(\varphi_{(t)}\right)
$$

\section{Aerodynamic Drag and Rolling Resistance}

Aerodynamic drag and rolling resistance can be modelled with equations with empirical coefficients. For this simulation a vehicle speed is fairly constant. Thus to simplify programming, a constant of $T_{\text {wdrag }}=30 \mathrm{Nm}$ has been applied at the tire as a combination of both.

\section{Excitation Torque Vector}

The global torque vector for (1) includes the forcing functions and gear lash offset:

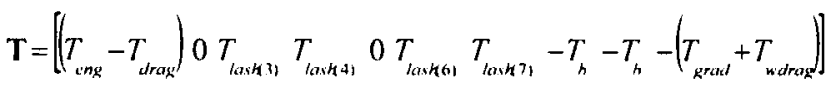

\section{SIMULATION STUDIES}

In this article, two simulation studies are compared. Both used the forcing functions described above. The first is with the damping ratios of Table 3 - shuffle mode damping of $8.2 \%$. This is a reasonable assumption for damping in an AT powertrain with unlocked torque converter. The second is with the dynamic drag damping coefficient reduced to $0.5 \mathrm{Nms} / \mathrm{rad}$ providing a damping ratio of $2.5 \%$. This provides a comparison for the effect damping driveline shuffle has on clunk. For the first simulation component speeds are shown in Figure 8 . The engine, transmission and vehicle speeds reduce slightly as the vehicle is driven up the crest and at around $4 \mathrm{~s}$ the road gradient changes from positive to negative and the driver tips out the engine torque to practically zero driving torque. Shortly afterwards the brake is tapped and held on, as shown in Figure 6 . Driver behavior is assumed to be arbitrary (depends on personality) and in this case a fairly constant vehicle speed has been maintained. In Figure 8 , from $4.5 \mathrm{~s}$ $4.75 \mathrm{~s}$ the effects of gear impacts in the transmission and final drive can be seen. The peak value of the transient impact velocity can be used as one measure for clunk severity.

The shaft plots (Figures 9 and 10) show the rigid body and transient motion of the driving system, as well as the harmonics of engine firing (Figure 9). First we have a transient oscillation from a slightly unbalanced initial condition. Then as the car rises the crest the displacement gradually reduces (though these first 4 seconds are not shown in plot). The change in torque is large but the time is long so there is no transient vibration. From 4 to 4.2 seconds the engine tips out. This is enough time for a cycle of the shuffle mode so some of the response is already decaying before tip-out is complete. Meanwhile the solution mostly just follows the path of rigid body motion. This shows that the damping of the shuffle mode has some significant effect on the occurrence of the first clunk as long as the impulse is not very short (in time). For a true step function tip-in or tip-out, it will have little effect for the first cycle of response on clunk. For this driving situation the 
shaft response plots show that there was no clunk purely from engine tip-out - this is because the mean load was still sufficiently high and the transient vibration not large enough for gear separation. This does not discount the typical relationship between shuffle and clunk which will occur from large tip-in/out events under the presence of low mean load (especially with light damping such as in MT powertrains). In this driving situation clunk would not have occurred in this instance if not for the braking action adding further transient oscillations and rigid body motion. This shows it is very dependent on driver behavior. The sharp release of the brake at $4.5 \mathrm{~s}$ and reapplication precipitates large transient oscillations mainly exciting shuffle and axle modes. Due to the low mean torque in the powertrain the gears separate into lash and undergo several low frequency single-sided impacts with resulting high frequency single-sided impacts for a short duration each time the gears reengage. (The impacts from low frequency vibration would excite the higher modes of the powertrain due to the broadband nature of an impulse). Figures 11 and 12 show the transmission and final drive mesh relative displacements. The first gear separation (4.50-4.55s) occurs largely due to the change in rigid body twist when the brake is released. The next two main impacts (4.554.6s) are largely due to the excitation of axle modes in the powertrain (these three impacts are occurring at around $30 \mathrm{~Hz}$ ). At around $4.68 \mathrm{~s}$ another small separation occurs - finally due to driveline shuffle and in combination with axle oscillations. Referring back to Figure 10 the combination of these two modes is quiet clear from $4.6 \mathrm{~s}$ onwards.

Unlocked torque converters provide high damping in AT powertrains, however as the next result will show this does not necessarily prohibit the occurrence of driveline clunk. As mentioned a second simulation was run with the dynamic drag on the turbine reduced for a shuffle mode damping ratio of $2.5 \%$. Figures 13 and 14 show the relative displacements in transmission and final drive and Figure 15 compares for output shaft twist for both simulations. Up to $4.67 \mathrm{~s}$ the result is much the same this is as the change in rigid body motion from the braking transients and the axle mode vibrations (unchanged by TC drag damping) were the chief causes of gear separation. However the second simulation clearly has more impacts on the later cycles of shuffle response (4.65-4.75s). The difference in this particular simulation is not great, shuffle was not the main cause of the gear impacts in the first case and this similarity illustrates that. Increasing the damping ratio for the axle modes has a more significant effect in this instance.

These simulations provide an example of how the rigid body motion is an integral part of the problem. The shuffle and axle modes are functions of the impulses that drive the rigid body motion and also the shape and duration of these impulses. Some times clunk must occur - if the engine goes from driving to driven as a car goes down a hill a torque reversal must take place and again at acceleration. We would need to quantify the "events" or "causes" that are most objectionable. In this case the goal should be perhaps on attenuating the effects and also in understanding the true behavior. In future research, we must clearly find how to attenuate the effects in these situations and then develop effective and practical means in application in passenger cars.

\section{SOME SIMULATION ISSUES}

Simulations for stiff systems present significant challenges with the inclusion of multiple non-linearities such as clearance algorithms and stick-slip. Several issues for improving simulation times and ensuring accuracy of solutions include:

- Reducing numerical stiffness through appropriate model reduction and non-dimensionalization of system parameters

- Using dedicated solvers orientated to these types of problems [13]

- Using smoothening functions for non-linear mesh stiffness [14]

- Comparison with experimental results

- Assessing numerical convergence

For our simulations convergence was studied by doubling and halving the maximum time step. The solutions were practically identical. The high frequency response after impacts was less accurate for larger time stepping and more accurate for smaller time stepping naturally. For this model the solutions were not difficult to achieve. However, the model of Figure 5 presents a much stiffer problem. In this model the planetary gears are included with six degrees of freedom (one for each gear) and backlash applied for each planetary gear mesh. The model is also reduced from the detailed powertrain system and also captures the main modes of response closely. For gear shifting the global coordinate is piecewise as various planetary gear coordinates are constrained/driven to achieve certain gear ratios. The solution is parametric during the inertia phase of a gear shift. In addition clutch engagement pressure oscillations or unstable friction characteristics (that could excite clutch judder) and stick-slip on engagement all add further non-linearities, as well as interactions among them. This will be a focus of future work along with the driveline vibration experiments for model verification, using the test rig of Figure 1.

\section{CONCLUSION}

A model including multiple non-linearities for gear backlashes has demonstrated the occurrence of driveline clunk during a typical driving situation for an AT powertrain. The simulation includes the system related effects of the powertrain system, including engine surging, shaft stiffness, component inertias, engine harmonics, drag torques, braking, viscous damping and vehicle load. The simulation shows that the occurrence of clunk is not only due to shuffle. Further, it might not be largely affected by torque converter damping. Although in harsh tip-in/out, this is the case. Rigid body motion of 
the powertrain and low mean torque are other significant factors. The axle mode when braking is applied also plays a role. Reducing the rate of application of tipin/out or brake torque will attenuate the problem, however, this is to the detriment of vehicle response. The same principles apply for simulating clunk in combined transient and rigid body motion in AT gear shifting though friction non-linearities would need to be included, then leading to a simulation of combined clutch engagement judder, stick-slip and clunk.

\section{ACKNOWLEDGMENTS}

Financial support for this research is provided jointly by the Australian Research Council (Grant No.C00107787), the University of Technology, Sydney, Australia and lon Automotive Systems, Sydney, Australia.

\section{REFERENCES}

[1] S.-J.Hwang, J.-S.Chen, L.Liu and C.-C.Ling, Modeling and Simulation of a Powertrain-Vehicle System with Automatic Transmission, Int. J of Vehicle Design, 2000, Vol.23, No.1/2, pp.145-160

[2] H.-S.Jo, Y.-I.Park, J.-M.Lee, W.-J.Jang, J.-H.Park and W.-S.Lim, A Study on the Improvement of the Shift Characteristics for the Passenger Car Automatic Transmission, Int. J of Vehicle Design, 2000, Vol.23, No.3/4, pp.307-328

[3] N.Zhang, A.Crowther, D.K.Liu, J.Jeyakumaran, A Finite Element Method for the Dynamic Analysis of Automatic Transmission Gear Shifting with a 4DOF Planetary Gearset Element. Proc. of Inst. of Mech. Eng. Part D: Journal of Automobile Engineering 217, 2003, pp.461-473

[4] N. Zhang. Dutta-Roy.N, 'Investigation into Dynamics and Stability of a Powertrain with Half-Toriodal Type CVT', 2004 SAE Conference on Continuously Variable and Hybrid Transmissions, SAE Paper No. 2004-342886

[5] R.Krenz, Vehicle Response to Tip-in/Tip-out. SAE Technical Paper 850967

[6] R. J. Comparin and R. Singh, Nonlinear Frequency Response Characteristics of an Impact Pair, Journal of Sound and Vibration, 1998, 134(2), pp.259-290
[7] A. Crowther, N. Zhang, D. Liu, J.M. Jeyakumaran, 'Analysis and Simulation of Clutch Engagement Judder and Stick-Slip in Automotive Powertrain Systems' Proc. of Inst. of Mech. Eng. Part D: Journal of Automobile Engineering, 2004, Vol 218 (D10)

[8] A. Crowther, N. Zhang, 'Torsional Finite Elements and Non-Linear Numerical Modelling in Vehicle Powertrain Dynamics' Journal of Sound and Vibration (accepted for publication 19 July 2004)

[9] M.T.Menday, H.Rahnejat, M.Ebrahimi, Clonk: an Onomatopoeic Response in Torsional Impact of Automotive Drivelines. Proc. of Inst. of Mech. Eng. Part D: Journal of Automobile Engineering, 1999, Vol.213, pp.349-357

[10] A. Farshidianfar, A.Ebrahimi, H.Bartlett, Hybrid Modelling and Simulation of the Torsional Vibration of Driveline Systems. Proc. of Inst. of Mech. Eng. Part D: Journal of Automobile Engineering, 1999, Vol. 215, pp.217-229

[11] J.W.Biermann, B.Hagerodt, Investigation of the Clonk Phenomenon in Vehicle Transmissions Measurement, Modeling and Simulation. Proc. of Inst. of Mech. Eng. Part K: Journal of Multibody Dynamics, 1999, Vol.213, pp.53-60

[12 L.F.Shampine, M.W.Reichett The Matlab ODE Suite, SIAM Journal of Scientific Computing, 1997, Vol.18, pp.1-22

[13] C.Padmanabhan, R.C.Barlow, T.E.Rook, R.Singh, Computational Issues Associated with Gear Rattle Analysis, ASME Journal of Mechanical Design, 1995, Vol.117, pp.185-192.

[14] T.C.Kim, T.E.Rook,R.Singh, Effect of Smoothening Functions on the Frequency Response of an Oscillator with Clearance Non-Linearity, Journal of Sound and Vibration, 2003, Vol 263(3), pp.665-678

\section{CONTACT}

Ashley R. Crowther

Faculty of Engineering, University of Technology, Sydney

PO Box 123 Broadway 2007

crowther@eng.uts.edu.au 


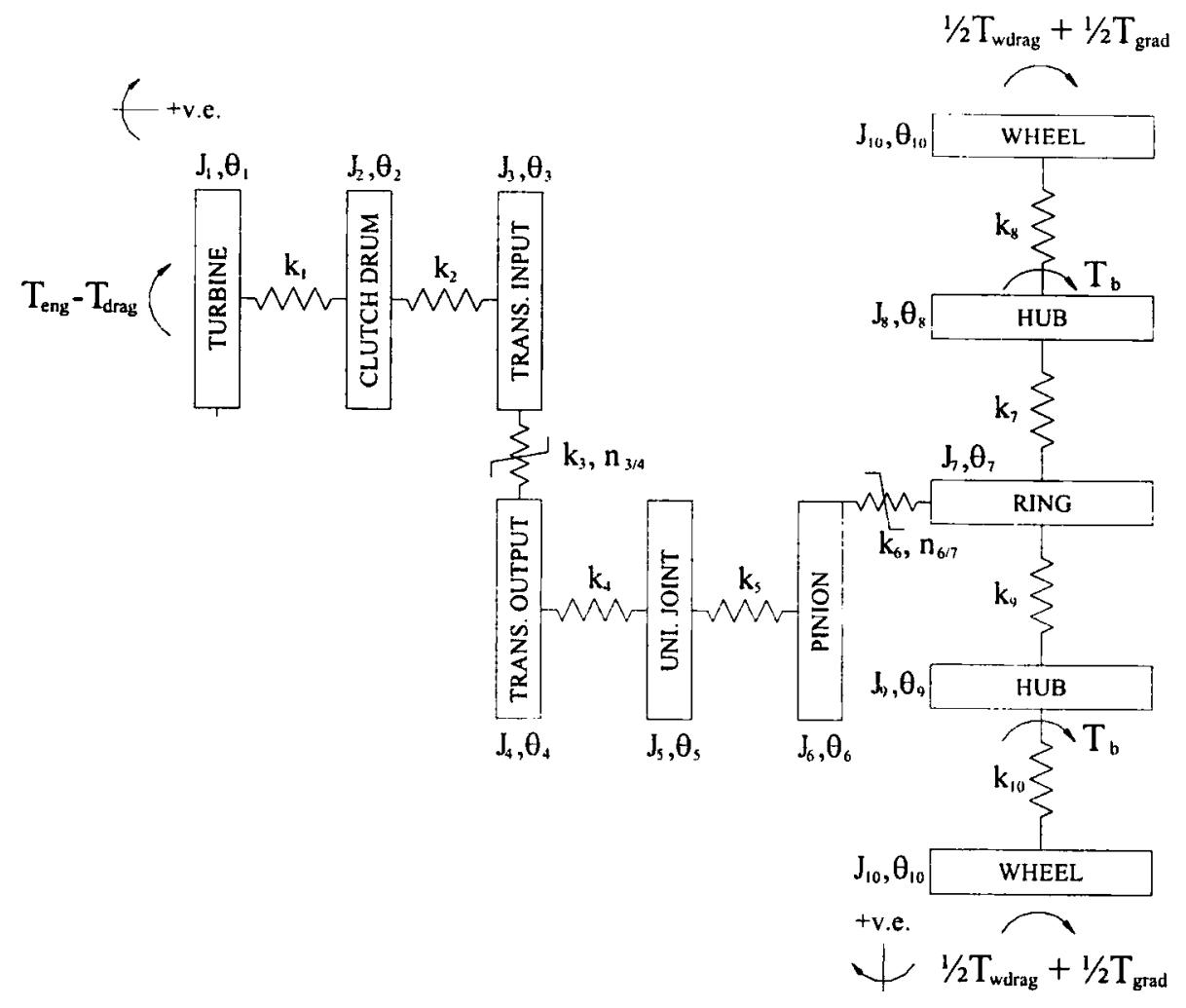

Figure 3. Reduced Powertrain Model with 10 DOF.

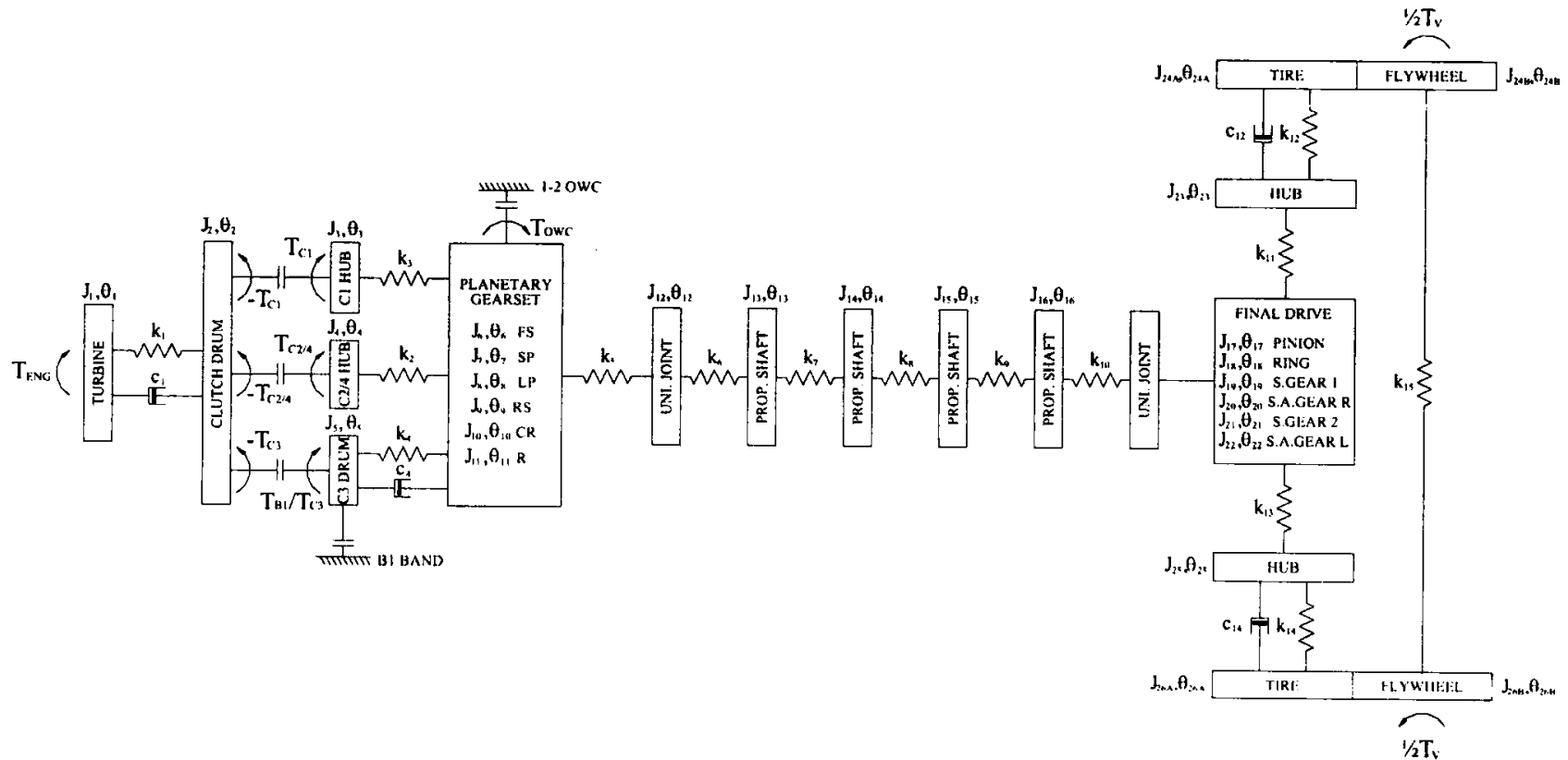

Figure 4. Detailed Powertrain Model 


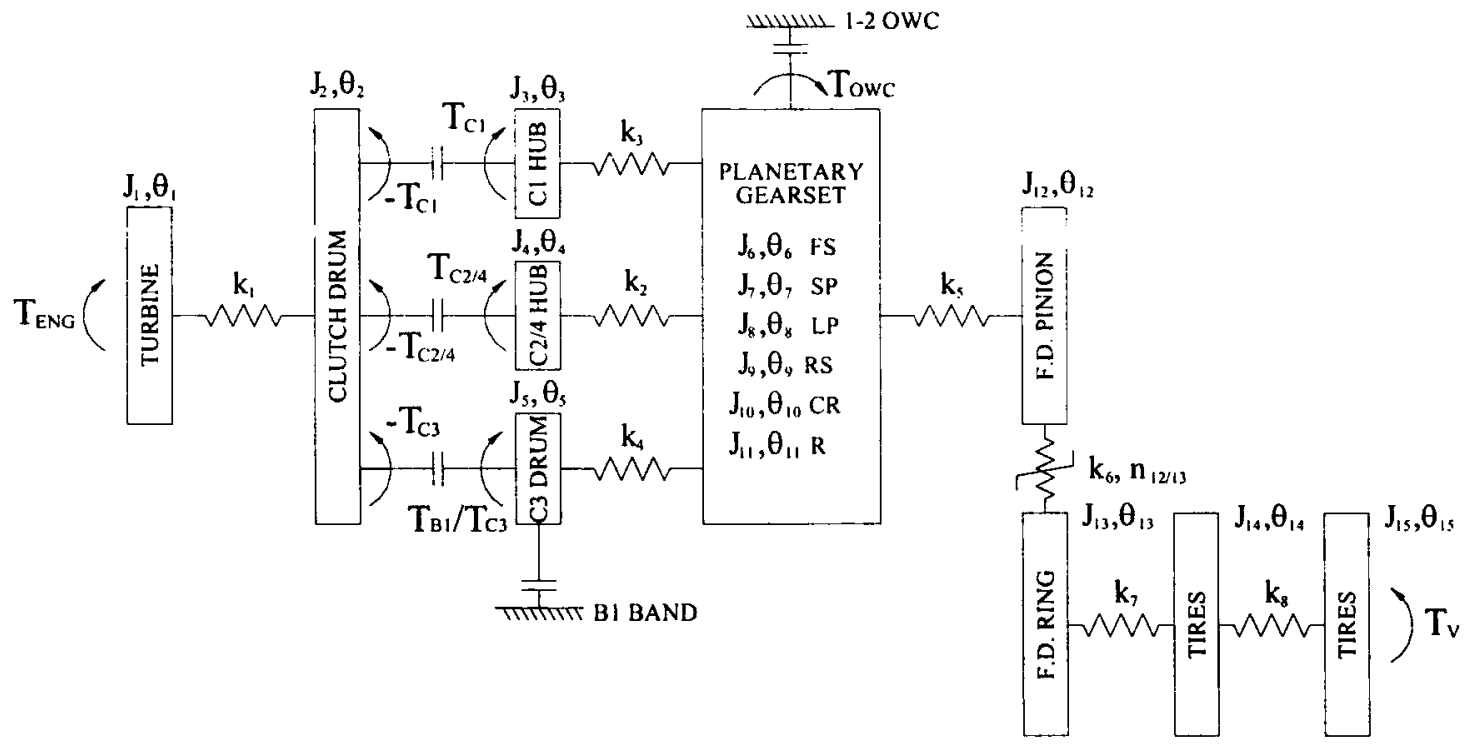

Figure 5. Powertrain Model for Gear Shifting with Focus on Clunk and Clutch Stick-Slip Phenomena.

\begin{tabular}{|c|c|c|c|c|c|c|c|c|c|c|}
\hline & \multicolumn{2}{|c|}{ Driveline shuffle } & \multicolumn{2}{|c|}{$\begin{array}{c}\text { Global and Axle } \\
\text { tramp mode }\end{array}$} & \multicolumn{2}{|c|}{$\begin{array}{c}\text { Global and axle } \\
\text { mode }\end{array}$} & \multicolumn{2}{|c|}{$\begin{array}{l}\text { Transmission } \\
\text { and Driveline I } \\
\end{array}$} & \multicolumn{2}{|c|}{$\begin{array}{c}\text { Transmission } \\
\text { and Driveline II }\end{array}$} \\
\hline Natural Frequencies $(\mathrm{Hz})$ & \multicolumn{2}{|c|}{6.54} & \multicolumn{2}{|c|}{32.3} & \multicolumn{2}{|c|}{33.2} & \multicolumn{2}{|c|}{142} & \multicolumn{2}{|c|}{250} \\
\hline $\begin{array}{l}\text { turbine } \\
\text { clutch drum } \\
\text { transmission driving gears } \\
\text { transmission driven gears } \\
\text { uni joint } \\
\text { final drive pinion }\end{array}$ & $\begin{array}{l}1.00 \\
0.98 \\
0.97 \\
0.66 \\
0.64\end{array}$ & $\begin{array}{l}1.00 \\
0.99 \\
0.97 \\
0.66 \\
0.63\end{array}$ & $\begin{array}{l}-0.13 \\
-0.05 \\
-0.02 \\
-0.01 \\
0.06\end{array}$ & $\begin{array}{l}-0.12 \\
-0.05 \\
-0.02 \\
0.00 \\
0.06\end{array}$ & $\begin{array}{c}-0.19 \\
-0.09 \\
-0.03 \\
-0.02 \\
0.07\end{array}$ & $\begin{array}{r}-0.18 \\
-0.08 \\
-0.03 \\
-0.01 \\
0.08\end{array}$ & $\begin{array}{c}-0.08 \\
0.80 \\
1.00 \\
0.69 \\
0.84\end{array}$ & $\begin{array}{c}-0.09 \\
0.76 \\
0.96 \\
0.70 \\
0.86\end{array}$ & $\begin{array}{c}0.02 \\
-0.54 \\
-0.30 \\
-0.18 \\
0.37\end{array}$ & $\begin{array}{c}0.02 \\
-0.57 \\
-0.33 \\
-0.16 \\
0.39\end{array}$ \\
\hline and uni joint & 0.61 & 0.60 & 0.13 & 0.13 & 0.18 & 0.18 & 1.00 & 1.00 & 1.00 & 1.00 \\
\hline final drive ring & 0.18 & 0.18 & 0.0 & 0.0 & 0.06 & 0.06 & 0.29 & 0.29 & 0.30 & 0.30 \\
\hline hub & 0.05 & 0.05 & 1.00 & 1.00 & 0.24 & 0.25 & -0.01 & 0.00 & 0.00 & 0.00 \\
\hline hub & 0.05 & 0.04 & -0.25 & -0.26 & 1.00 & 1.00 & 0.00 & 0.00 & 0.00 & 0.00 \\
\hline Tire & .0 .01 & -0.01 & 0.00 & 0.00 & 0.00 & 0.00 & 0.00 & 0.00 & 0.00 & 0.00 \\
\hline
\end{tabular}

"bold values designate reduced model

Table 4. Mode Shape Comparison - Detailed Model versus Reduced 10DOF Model 

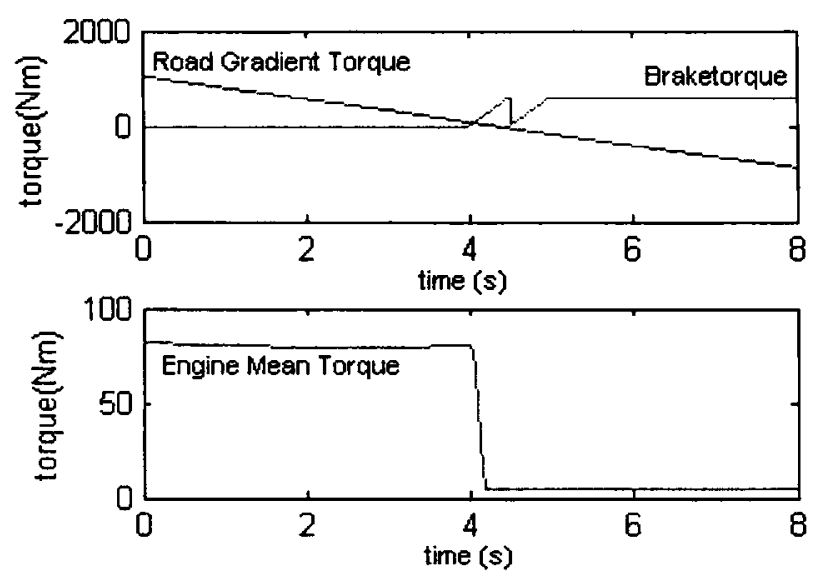

Figure 6. Engine, Road Gradient and Brake Torque Time Histories
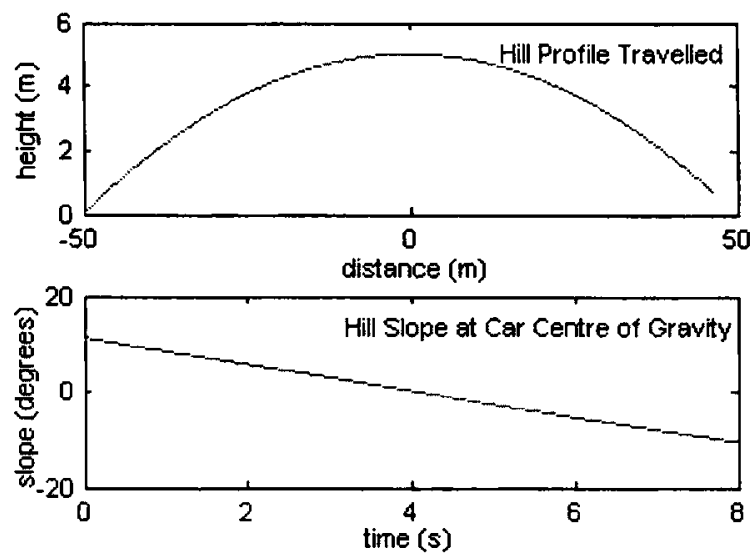

Figure 7. Assumed Road Profile and Slope as a Function of Time

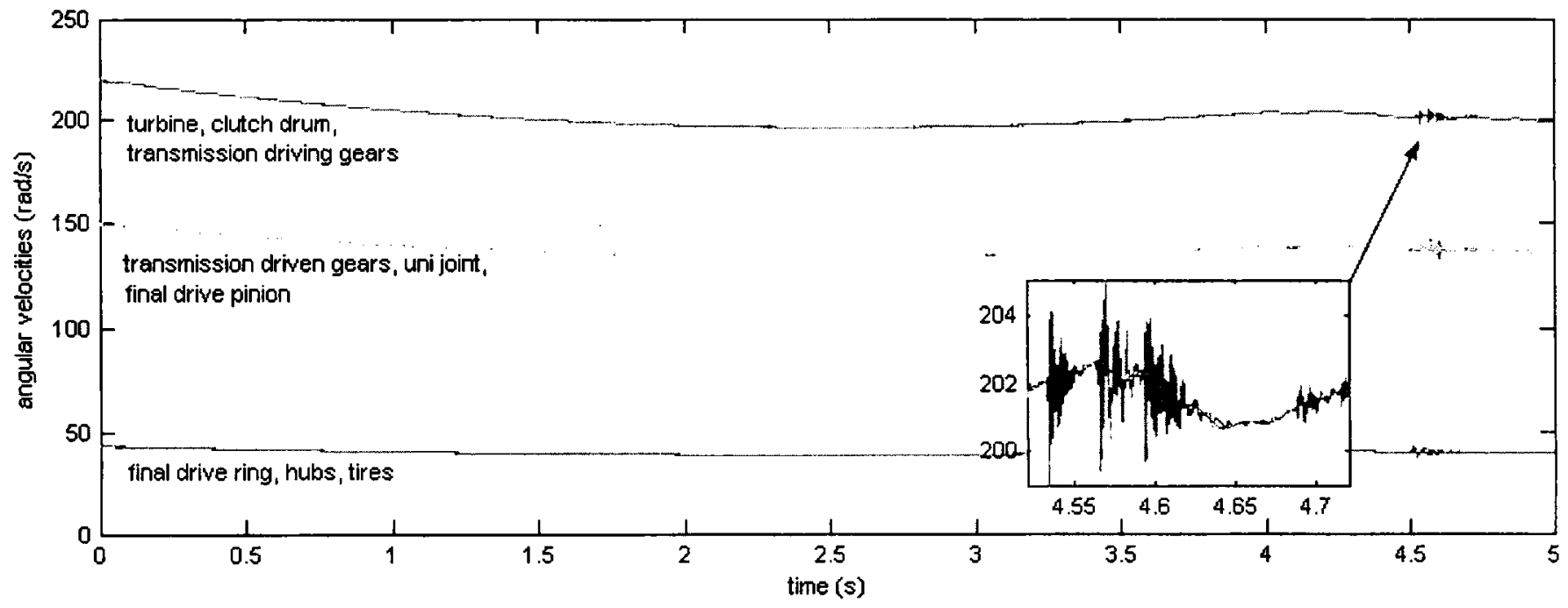

Figure 8. Simulated Component Speeds Given High Drag Damping in the Turbine

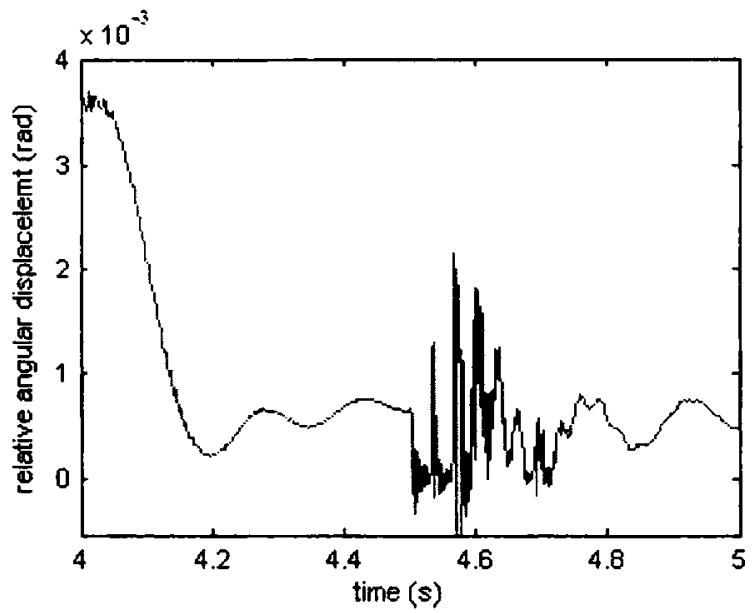

Figure 9. Input Shaft Twist Given High Drag Damping in the Turbine

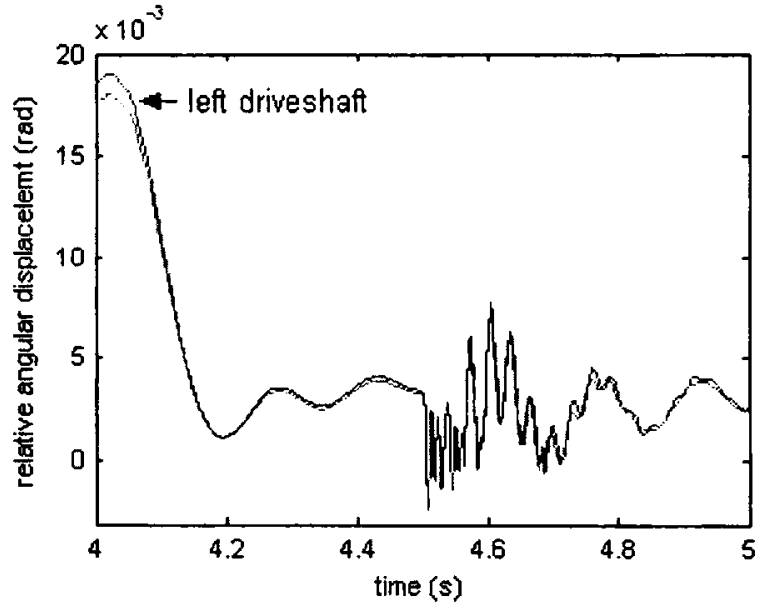

Figure 10. Driveshaft Twist Given High Drag Damping in the Turbine 


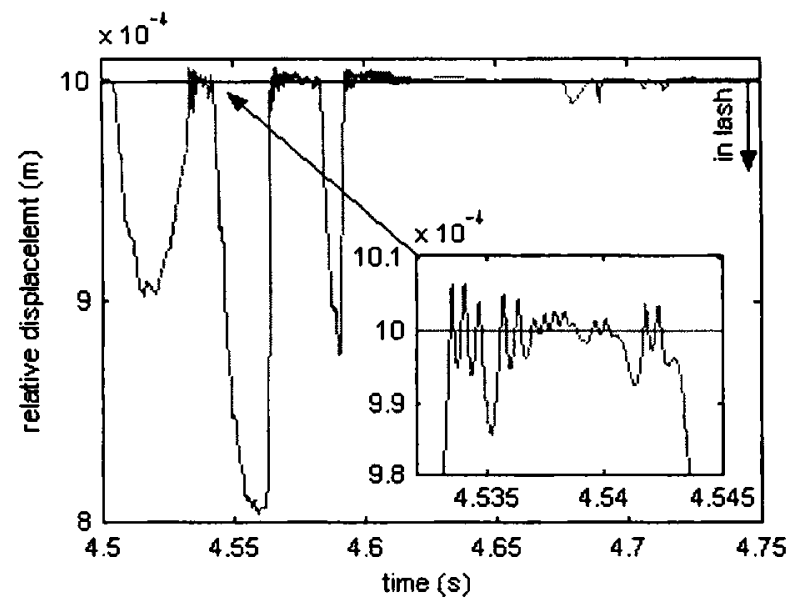

Figure 11. Relative Displacement in Transmission Given

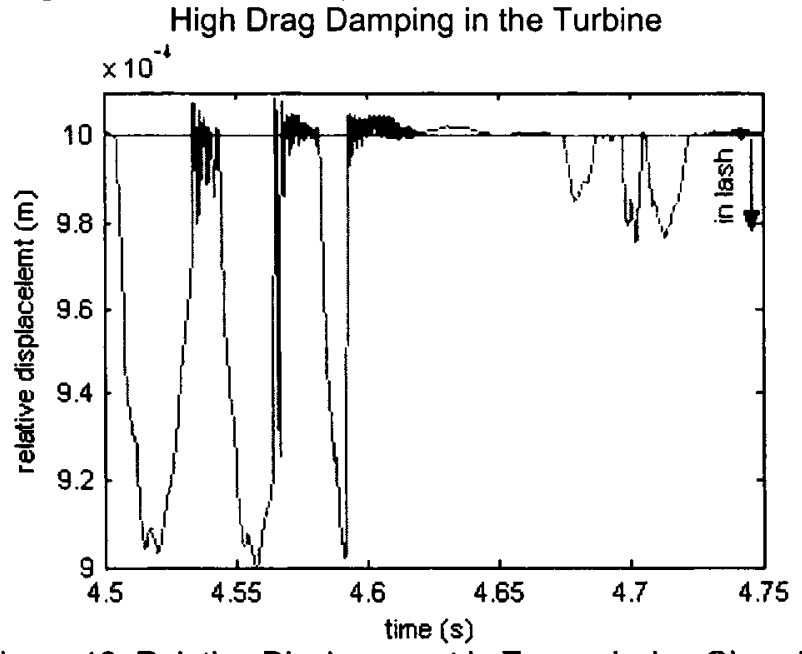

Figure 13. Relative Displacement in Transmission Given Low Drag Damping in the Turbine

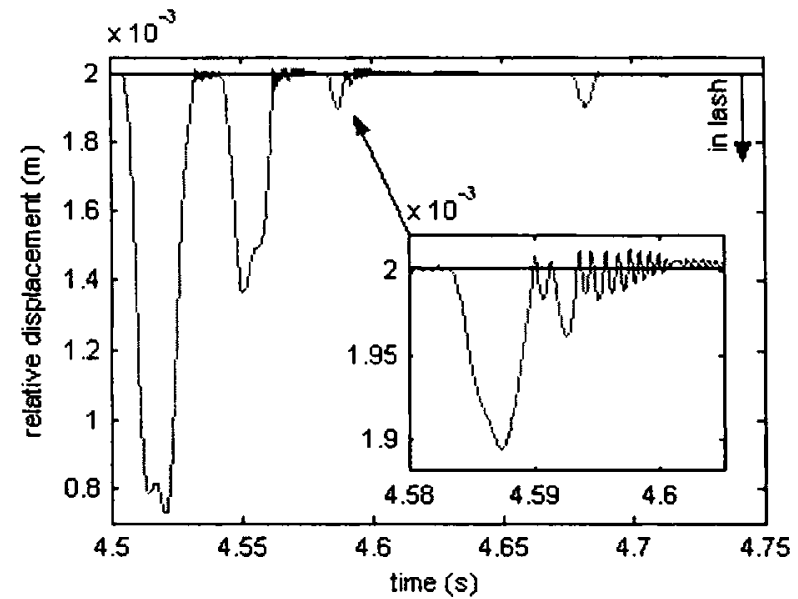

Figure 12. Relative Displacement in Final Drive Given

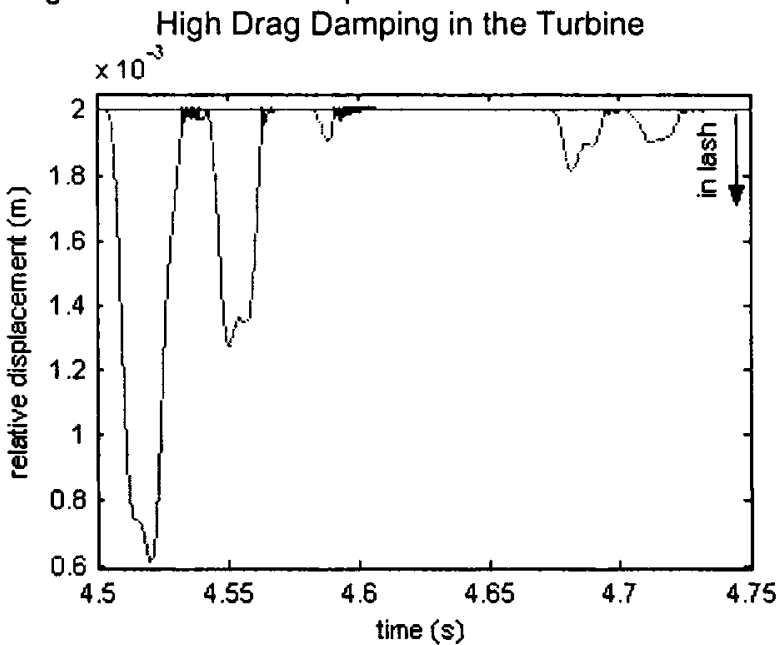

Figure 14. Relative Displacement in Final Drive Given Low Drag Damping in the Turbine
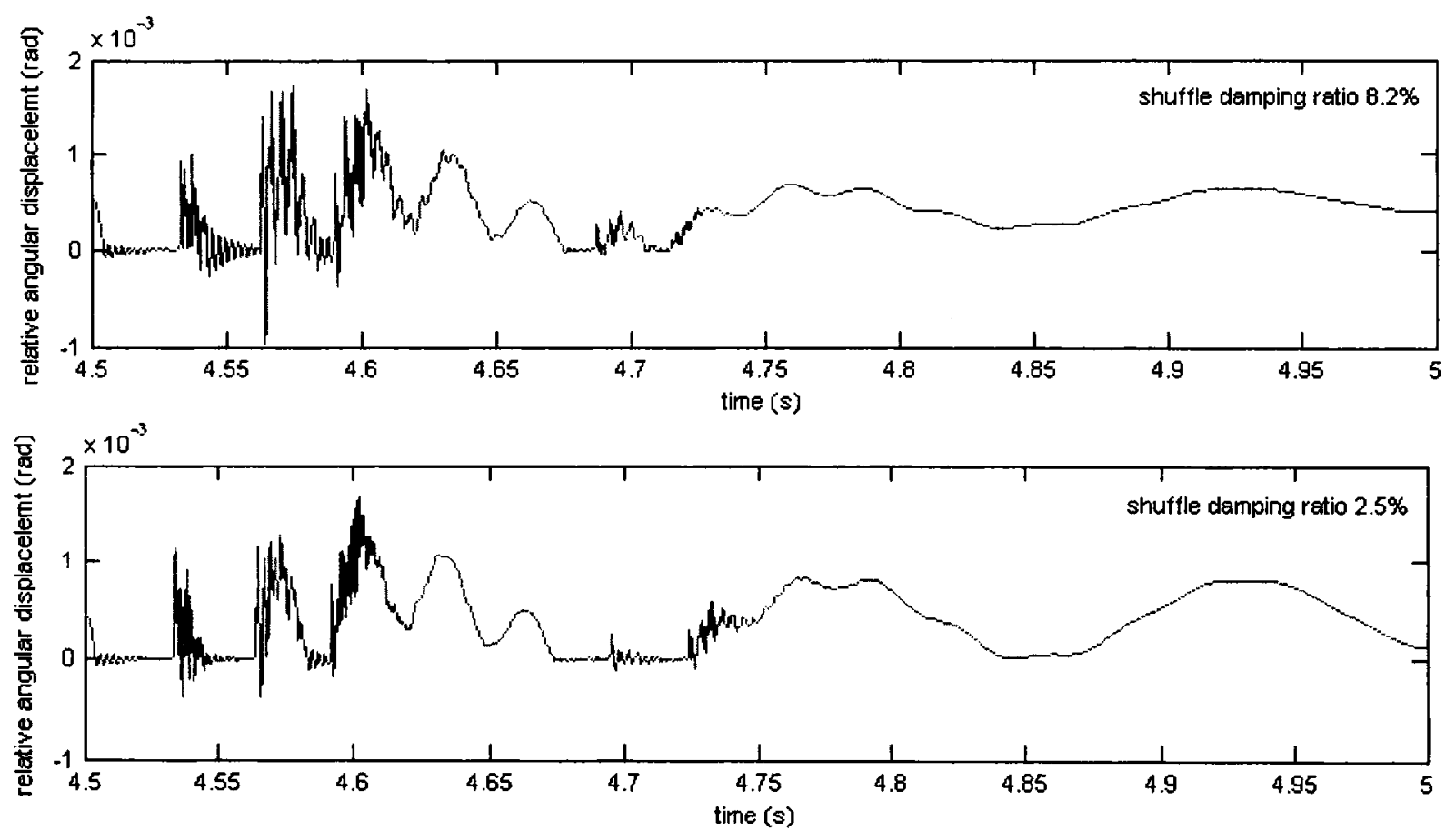

Figure 15. Output Shaft Twist Comparison Given High (top) and Low (bottom) Dynamic Drag Damping in the Turbine 